\title{
Pivotal power brokers: Theory and evidence on political fundraising
}

\author{
Franklin G. Mixon • Chena C. Crocker • \\ H. Tyrone Black
}

(C) Springer Science + Business Media B.V. 2006

\section{Erratum to: \\ Public Choice 123 (3-4): 477-493}

Part of the text of Endnote 17 from the article above was inadvertently omitted from the article during production. The full text of the endnote is as follows:

17. The aggregate nature of RPAC precludes use of DIST1, DIST2 and other variables found in the previous models using disaggregated data. During our work on this study the CRP periodically changed historical information on its website regarding the year of next election for some Senators, thereby creating some inconsistencies in the DIST series and impacting the results presented earlier. Thus, omitting the DIST series altogether, as use of the aggregate PAC contributions requires, provides the secondary benefit of eliminating variables with potential measurement error.

The online version of the original article can be found at: http://dx.doi.org/10.1007/s11127-005-7172-3

F. G. Mixon Jr. $(\bowtie) \cdot$ H. T. Black

Department of Economics, The University of Southern Mississippi, 118 College Drive 5072,

Hattiesburg, Mississippi 39406-0001, USA

C. C. Crocker

Graduate School of Management, The University of Southern Mississippi, USA 